\title{
Comparison of the diagnostic values of clinical examination, sonography and electrodiagnosis in the diagnosis of carpal tunnel syndrome
}

Zana Ramezani ${ }^{1}$, Sara Behafarid ${ }^{2}$, Foad Rahimi $^{3}$, Hajar Kashefi ${ }^{4}$

1. General practitioner, Student Research Committee, Kurdistan University of Medical Sciences, Sanandaj, Iran. ORCID ID: 0000-0001-5030-7383

2. Radiologist, Kurdistan University of Medical Sciences, Sanandaj, Iran. ORCID ID: 0000-0003-2618-3127

3. Assistant Professor, Orthopedic Department, Kurdistan University of Medical Sciences, Sanandaj, Iran., (Corresponding Author), Tel: 087-36222613, Email: Iran.foadrahimi76@gmail.com, ORCID ID: 0000-0002-2031-1418

4. MSc of Biostatistics, Social Determinants of Health Research Center, Research Institute for Health Development, Kurdistan University of Medical Sciences, Sanandaj, Iran. ORCID ID: 0000-0001-9603-0789

\begin{abstract}
Background and Aim: Carpal tunnel syndrome (CTS) is the most common peripheral mononeuropathy which is caused by nerve compression, in the wrist area (carpal tunnel). The use of ultrasound for the examination and diagnosis of musculoskeletal diseases has been increasing over the last few decades. The aim of this study was to compare the diagnostic values of clinical examination, sonography, and electrodiagnosis in the diagnosis of carpal tunnel syndrome.

Materials and Methods: In this cross-sectional study (descriptive-analytic) we examined 70 wrists with symptoms consistent with CTS. Sonography and neural conduction studies were performed. Demographic data included age, height, gender, dominant hand, and underlying diseases associated with CTS. Clinical examination was performed and median nerve cross section and thickness were measured by ultrasound. Then, the results of clinical examination, sonography, and neural conduction study were compared with one another.
\end{abstract}

Results: We examined 70 wrists with symptoms consistent with CTS. Among 70 symptomatic wrists, 91.4\% belonged to the women (mostly housewives) and the rest belonged to the men. The mean age of the patients was $49.56 \pm 11.63$ years. The results of $\mathrm{NCV}$, clinical examination, distal flexor retinaculum sonography and proximal sonography were positive in $82.9 \%, 67.1 \%, 45.7 \%$ and $32.9 \%$ of the patients respectively. The results of this study showed that sonography of the entrance of the carpal tunnel with a cut-off point of $8.5 \mathrm{~mm}^{2}$ had the highest diagnostic value with a sensitivity of $27 \%$ and a specificity of $42 \%$.

Conclusion: Measuring the median nerve surface area with ultrasound is useful for detecting and grading the severity of CTS, but it cannot replace neural conduction studies. The use of ultrasound as the first-line measure can be effective in decreasing the number of neurotransmission studies.

Keywords: Carpal tunnel syndrome, Clinical examination, Sonography, Electrodiagnosis

Received: Sep 9, $2018 \quad$ Accepted: Jan 19, 2020

How to cite the article: Zana Ramezani, Sara Behafarid, Foad Rahimi. Comparison of Diagnostic Value of Clinical Examination, sonography and Electrodiagnosis in the Diagnosis of Carpal Tunnel Syndrome. SJKU 2021; 25(6):68-78.

Copyright (C) 2018 the Author (s). Published by Kurdistan University of Medical Sciences. This is an open access article distributed under the terms of the Creative Commons Attribution-Non Commercial License 4.0 (CCBYNC), where it is permissible to download, share, remix, transform, and buildup the work provided it is properly cited. The work cannot be used commercially without permission from the journal 
بررسى مقايسهاى ارزش تشخيصى معاينه بالينى، سونوكر افى و الكترودياكنوزيس در تشخيص سندرم توفل كاريال

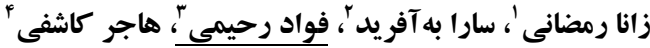

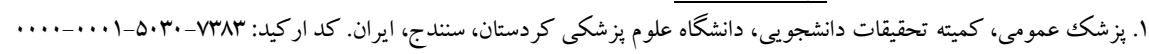

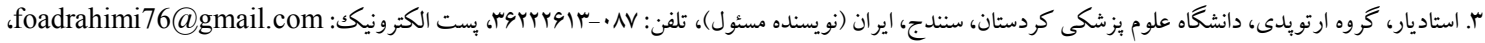

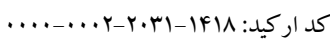

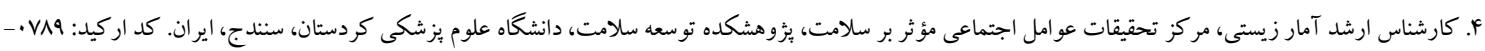

زمينه و هدف: سندرم تونل كاريال (CTS) شايعترين مونونوروياتى محيطى ناشى از تحتفشار قرار گرفتن عصب، در ناحيه مج

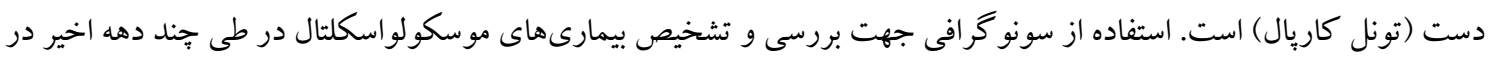

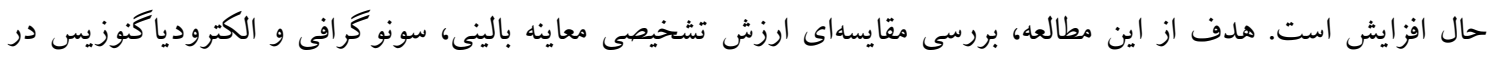
تشخيص سندرم تونل كاريال مىباشد.

مواد و روشها: اين مطالعه از نوع مقطعى (توصيفى - تحليلى) بوده كه در طى آن ·V متج دست با علائم منطبق با سندرم تونل

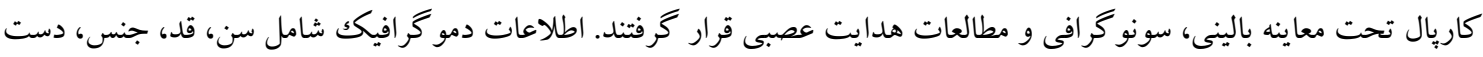

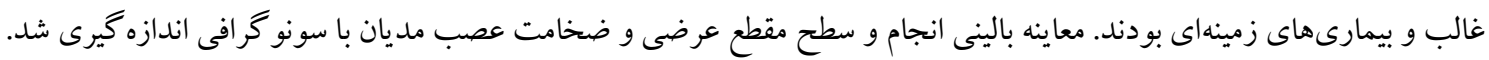

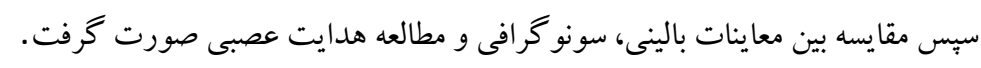

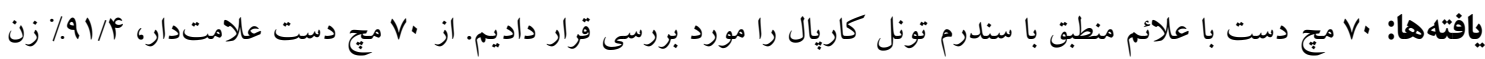

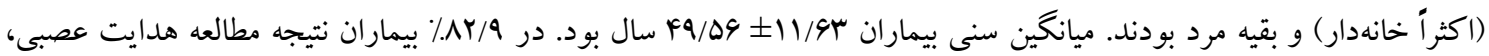

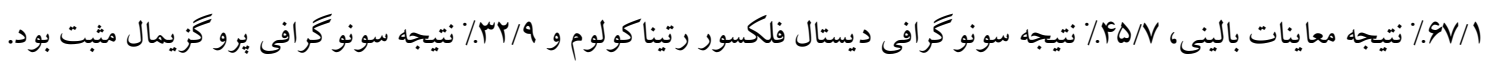

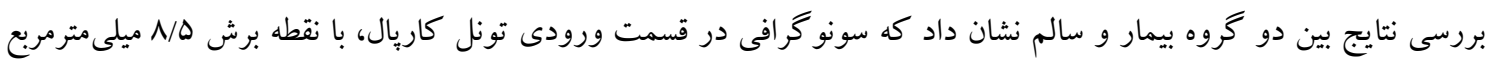

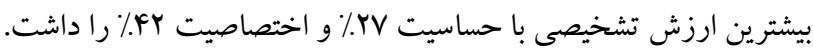

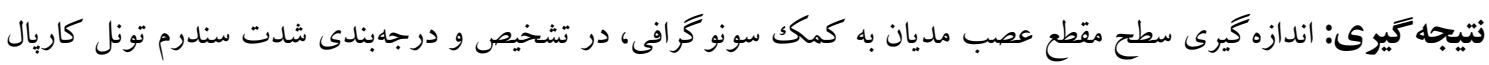

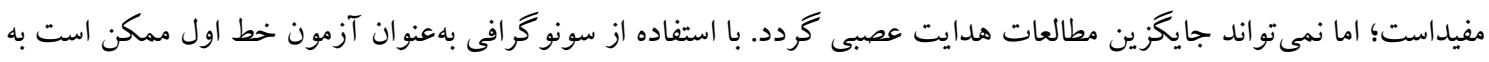
نحو مؤثرى ميز ان مطالعات هدايت عصبى كاهش يابد.

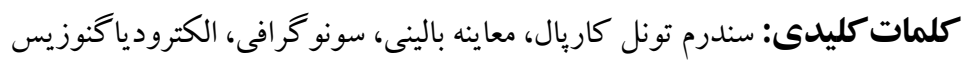

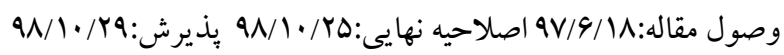


Vo براسى sقايسه اى ارزش تشفيص... V.

محدوده عصب مديان، تست فالن مثبت تلقى مىشود. در

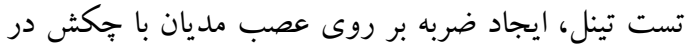
ناحيه مج دست ايجاد بارستزى و درد در مسير عصب مديان مىنمايد(A). فيليٍ در سال 1991 نشان داد كه تست فالن و تينل داراى حساسيت AV/٪ و اختصاصيت 99٪ است(9). از

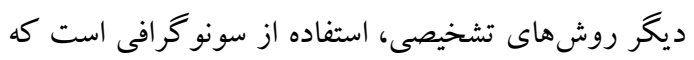
به نسبت NCV علاوه بر دسترسى آسانتر و غيرتهاجمى بودن براى بيماران، باعث تحميل هزينه و صرف زمان كمتر

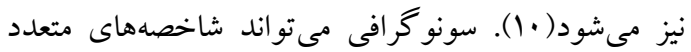
عصب مانند تغيير سيخنال، افزايش سطح مقطع، بهن شدرن عصب مديان و تورم فلكسوررتيناكولوم را نشان دهد؛ ولى حساسيت و ويزگى اين متغيرهاى تشخيصى در مطالعات،

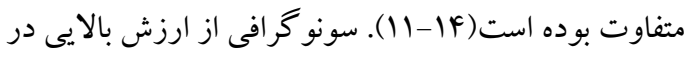
تشخيص ضايعات فضا كير تونل كاريال، آنومالىهاى عضلانى و تنوسينويت برخورداراست. با وجود اينكه سونو گرافى بهعنوان يك وسيله تشخيصى در مطالعات،

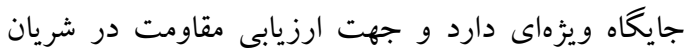
مدين در سندرم تونل كاريال و تعيين وارياسيونهاى

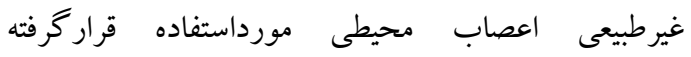
است (19,19)؛ اما مطالعات محدودى در زمينه استفاده از آن در بيماران با تشخيص احتمالى تونل كاريال انجامشده است

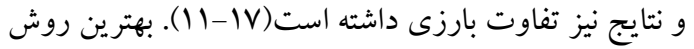
(استاندارد طلايى) براى تشخيص، تعيين شدت و همجنين

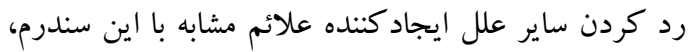

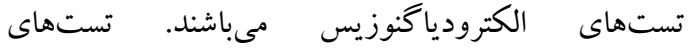
الكترودياكنوزيس كه به بررسى فيزيولوزيك اعصاب محيطى مى يردازند، در تشخيص اين بيمارى به علت اينكه

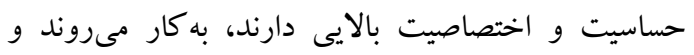
مىتوان برنامه درمانى اعم از درمان طبى يا جراحى را بر

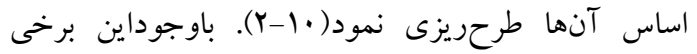
فاكتورهاى مخدوش كننده، همجِون تعريق، خيس بودن و دماى دست بيمار حين انجام تست، سن بيمار، مهارت و

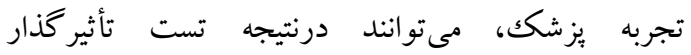
باشد(1),19). تحقيقات زيادى نشان داده است كه در
مقدمه

سندرم تونل كاريال ( Carpal Tunnel Syndrome, مقده شايعترين مونونوروياتى فو كال ناشى از تحتفشار (CTS

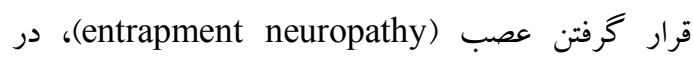

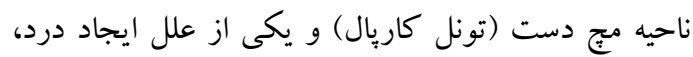

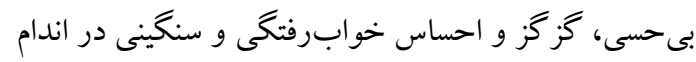

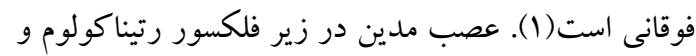
بر روى تاندونهاى فلكسور قرار دارد(Y). فشار تونل نرمال در حدود Y/ه ميلىمتر جيوه است كه در اين بيمارى به بr

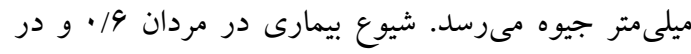

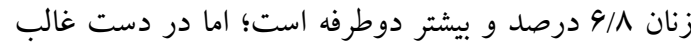

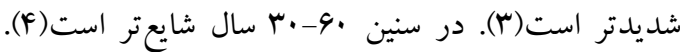

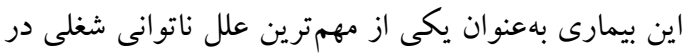
افراد مطرح است(ه). اكثر موارد سندرم تونل كاريال

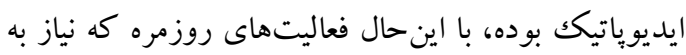

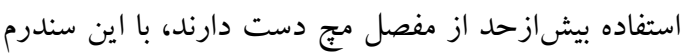

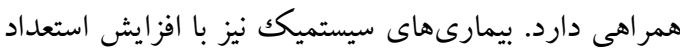

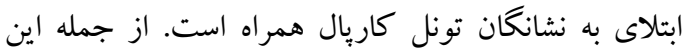

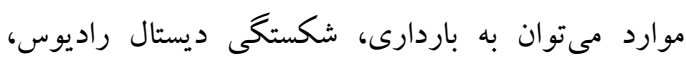

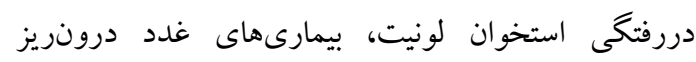

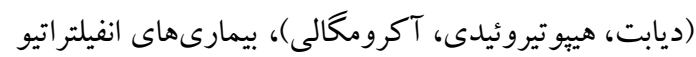
(آميلوئيدوز)، بيمارىهاى بافت همبند (آرتريت روماتوئيد)، بيمارىهاى عفونى و التهابى (سار كوئيدوز، توبر كلوز، لايم)

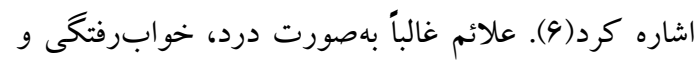

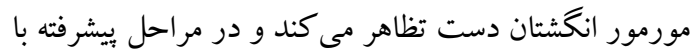
آتروفى عضلات تنار و ضعف عضلانى در دستها همراه است(V). براى تشخيص اين بيمارى از شرححال و معاينه

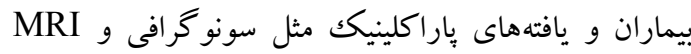
استفاده مىشود. با اينحال بهترين روش تشخيصى،

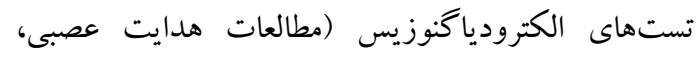
(NCV

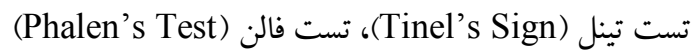
است. در تست فالن هردو مجج دست به مدت يكك دقيقه در

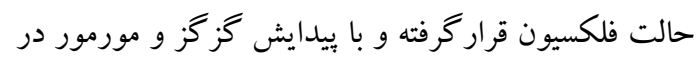


دقيق) مراجعه كننده به مطب ارتويدى در سندج انجام

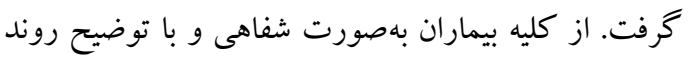

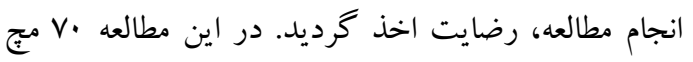
دست با علائم منطبق با سندرم تونل كاريال موردبررسى قرار گرفت. افرادى كه سابقه ابتلا به بيمارىهاى مقلد علائم

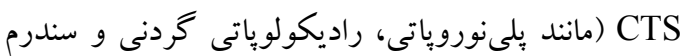
دهانه خروجى قفسه سينه، double-crush syndrome)، سابقه مصرف داروهايى كه باعث نوروياتى مى شوند، سابقه جراحى و تزريق، شكستخى مج و تروماهاى مكرر به دست،

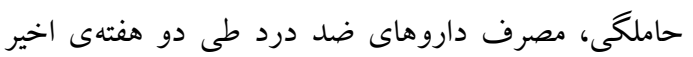
جهت تسكين CTS، سابقه بيمارىهاى زمينهاى مثل كم كارى تيروئيد، نقرس، لويوس، آرتريت روماتوئيد، نارسائى مزمن كليه و آكرومگالى را داشتند، از مطالعه

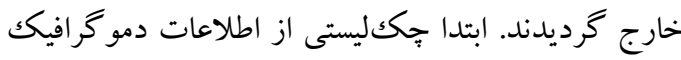
شامل سن، جنس، قد، وزن، شغل، دست غالب، دست بيمار، بيمارىهاى زمينهاى، سابقه تروما و جراحى و تزريق در مج دست و وجود آتروفى در عضله تنار يا اختلال حسى

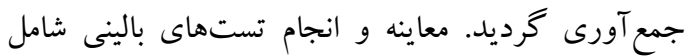

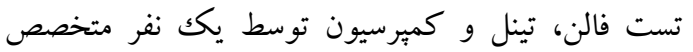

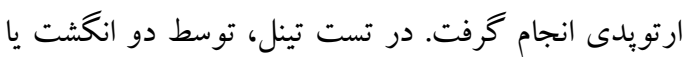
جكش معاينه، در مسير عصب مدين ناحيه مج دست بهطور

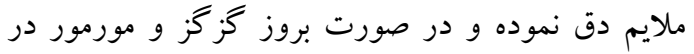

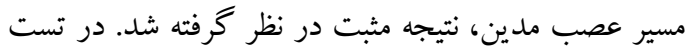
فالن بيمار بهطور فعال مج دست خود را براى مدت .9 ثانيه در حالت كاملاً خميده (فلكسيون مج دست) قرار داده و در

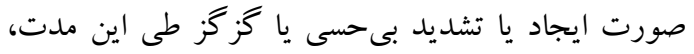
آزمون مثبت گزارش شد(ب/). در آزمون كميرسيون، جنانجه فشار انگشتان دست بر روى محل تونل كاريال در

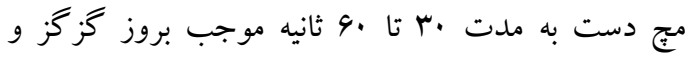
كرختى يا تشديد آن شد، آزمون مثبت در نظر كرفته شد(YY). اطلاعات حاصل از معاينات در جکك ليست وارد شد. سبس بيماران تحت آزمونهاى الكتروفيزيولوزيكك جهت اثبات سندرم تونل كاريال و بهعنوان (EMG,NCV) استاندارد طلايى قرار گرفتند. اين آزمون در تمام بيماران
مراحل اوليه CTS احتمال نرمال بودن نتايج و در موارد

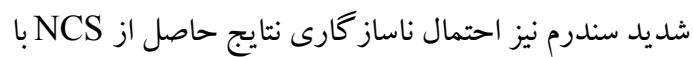
يافتهاى بالينى وجود دارد. علاوه بر اين NCS قادر نيست

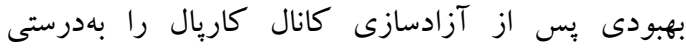

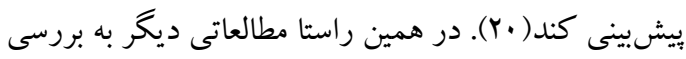
ارزش هركدام از روشها بهتنهايى يا در مقايسه باهم يرداختهاند. بهعنوانمثال در مورد معاينات بالينى نتايج

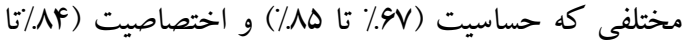
99٪) را براى تست فالن بيان كردهاند و براى تست تينل نيز اعداد متفاوتى ذكرشده است(1) (A-Y). همجِنين در مورد سونو گرافى، از بين معيارهاى مختلف، سطح مقطع عصب در ورودى و خروجى تونل كاريال بهترين نتايج را در

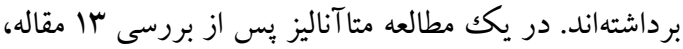

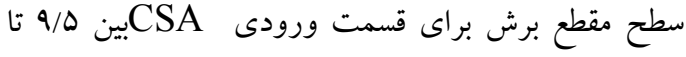

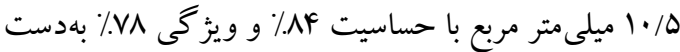

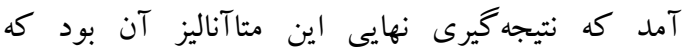
سونو گرافى در تشخيص سندروم تونل كاريال نمىتواند

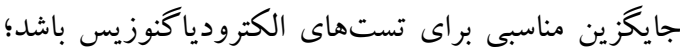

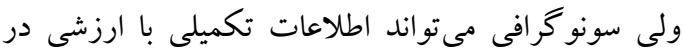
اختيار محققان قرار دهد(Y). از اينرو، با توجه به محدوديتهاى يادشده در هر كدام از روشهاى تشخيصى، بر آن شديم تا با طراحى مطالعه حاضر به بررسى و مقايسه ارزش تشخيصى هر كدام از روشهاى يادشده (معاينه و

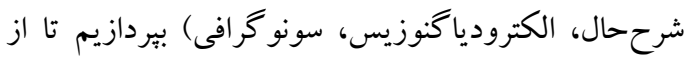

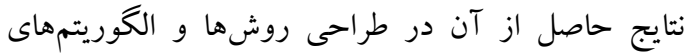
جديد تشخيصى كه براى بيماران و يزشكان از هر نظر بهتر باشد، استفاده شود.

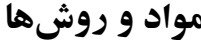

اين مطالعه از نوع مقطعى (توصيفى- تحليلى) بود كه بلصورت مقطعى در سهماهه آخر سال وها و سهماهه اول

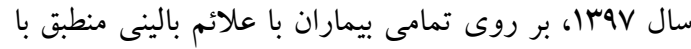

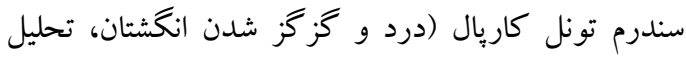

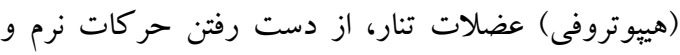




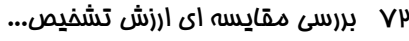

در نرمافزار SPSS نسخه الا، براى توصيف متغيرهاى كيفى از جداول و نمودارها (فراوانى و درصد) و براى متغيرهاى كمى از شاخصهاى مركزى و ير اكندگى استفاده شد. براى تمام آزمونها سطح معنىدارى برابر هـ٪ در نظر گرفته شد.

يافتهها

اين مطالعه بر روى تعداد •Vفر از بيماران با علائم منطبق با سندرم تونل كاريال مر اجعه كننده به مطب ارتويدى صورت

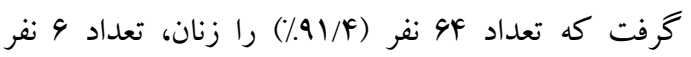

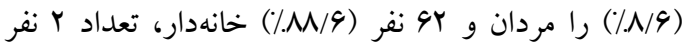

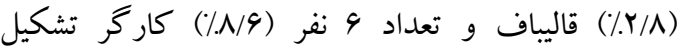

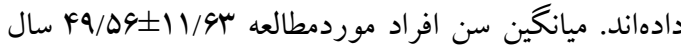
است. بيشترين سن الVو كمترين و ب سال است. ميانگين قد

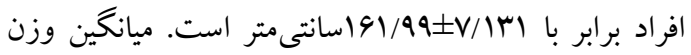
افراد V9 كيلو گرم است، بيشترين و كمترين وزن به ترتيب برابر با . .1 كيلو گرم است. در بين نمونههاى موردمطالعه تعداد سو مورد (•9٪) دست غالب آنها دست راست و

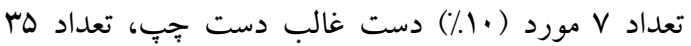
مورد ( •ه./) دست علامت دار آنها دست راست و هـ مورد

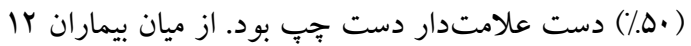

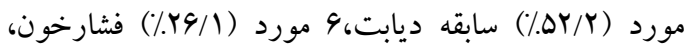

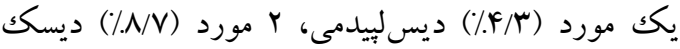
كمر و Y مورد (N/V) به هاييوتيروئيدى مبتلا بودند.

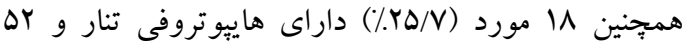
مورد (س/YK/ فاقل اين حالت بودند. در مطالعات

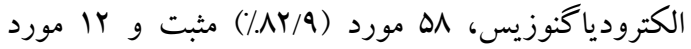
(\% ( ) منفى، در علائم بالينى (شامل تستهاى فالن، تينل

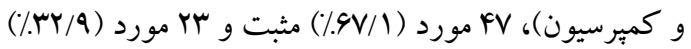
منفى، نتايج سونو گرافى خروجى كانال كاريال، بس مورد

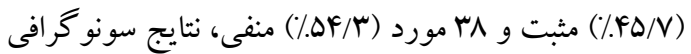

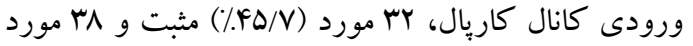

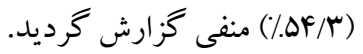

توسط يك متخصص نورولوزى باتجربه در زمينه تستهاى الكترودياكنوزيس انجام گرفت. انجام NCV با استفاده از دستخاه الكتروميو گرافى صورت گرفت. معيارهاى مثبت بودن اين تست شامل افزايش تأخير زمانى بتانسيل حسى بيشتر از (Sensory action potential distal latency) P/9 ميلىثانيه در فاصله If سانتىمترى مج دست، افزايش تأخير زمانى بتانسيل حركتى ( potential Motor action

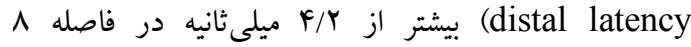
سانتىمترى متج دست و سرعت هدايت عصبى ( Nerve (Conduction Velocity NCV كمتر از متر بر ثانيه همراه با. (Across Wrist) نرمال عصب اولنار در ناحيه مج دست بود(YO). سيس صرفنظر از نتيجه حاصله و عدم اطلاع به سونولوزيست، تمامى اين بيماران تحت سونوگرافى قرار رفتند. سونوگرافى بهوسيله يكك بروب خطى انجام شد. تمامى اندازهيرىها توسط يكك متخصص راديولوزى صورت كرفت كه از معاينات و نتايج الكترودياكنوزيس بىاطلاع بود. جهت سونو گرافى بيمار به بشت دراز كشيده، آرنج بازو ساعد و كف دست در وضعيت سوياين قرار كرفت. مجج در حالت استراحت كامل و انگشتان نيمه خميده بودند. در دست بيمار، در محاذات مفصل راديو اولنار (ورودى تونل كاريال) و در محاذات قلاب استخوان جكشى (خروجى تونل كاريال) قطر قدامى خلفى و سطح مقطع عصب محاسبه شدند. علائم بالينى كه بر اساس نتايج تستهاى فالن، تينل و كميرسيون صورت كرفت بر اين اساس است كه در مواردى كه نتايج حداقل يكى از تستها مثبت بوده باشد علائم بالينى نشان از بيمار بودن شخص موردنظر است و در مواردى كه نتيجه هر سه تست منفى بوده باشد شخص سالم در نظر گرفته شده است. كات يوينت بهدستآمده براى سونو مرافى خروجى كانال كاريال

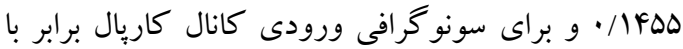
• • • • محاسبهشده است. نتايج حاصل با رعايت اصول اخلاقى و امانت و حفظ اسرار بيماران مورد تجزيهوتحليل آمارى قرار گرفت. يس از جمع آورى و وارد نمودن دادهها 
جدول امقايسه تستهاى معاينات بالينى و يافتههاى سونوكر افى در مقايسه با الكترودياكنوزيس بهعنوان استاندارد طلايى

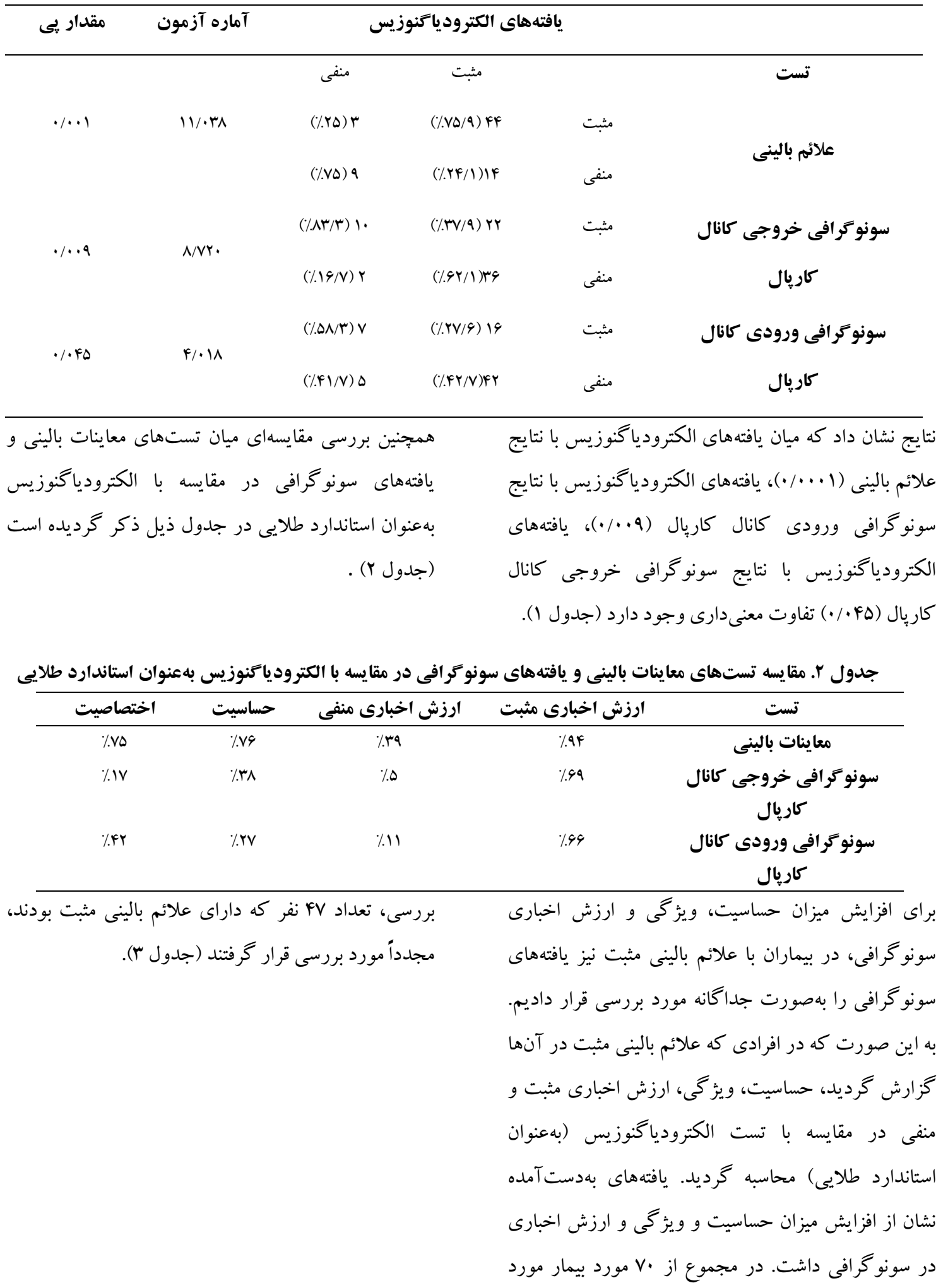


جدول ل. ويزگى و ارزش اخبارى سونو ز افى، در بيماران با علائم بالينى مثبت

\begin{tabular}{|c|c|c|c|c|}
\hline $\begin{array}{l}\text { اختصاصيت } \\
\text { CI (ه) (ه) }\end{array}$ & 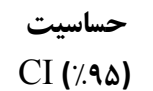 & 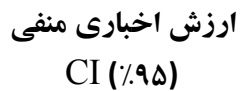 & 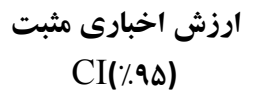 & 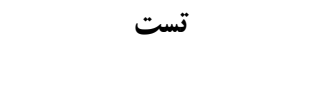 \\
\hline$\% \mathrm{VF} / \mathrm{I}$ & $\%$ \% & $\% .9 / 1$ & $\% q 4 / 4$ & سونو افى خروجى كانال \\
\hline$(94 / \Gamma-\Lambda \cdot / \mu)$ & $(G K / G-r N / \Delta)$ & $(r / r-\Lambda / \Delta)$ & $(\Lambda r / r-q \vee / \Delta)$ & كاريال \\
\hline$\% .95 / 1$ & $\% / \Lambda r / r$ & $\% / \Delta / \Lambda$ & $\% 9 r / r$ & سونو كر افى ورودى كانال \\
\hline$(W / / r-\Lambda \cdot / \Delta)$ & $(\vee \vee / \Delta-q \cdot / 4)$ & $(Y / r-\Lambda / \Lambda)$ & $(\Lambda \cdot / 4-q \Delta / \Lambda)$ & كاريال \\
\hline
\end{tabular}

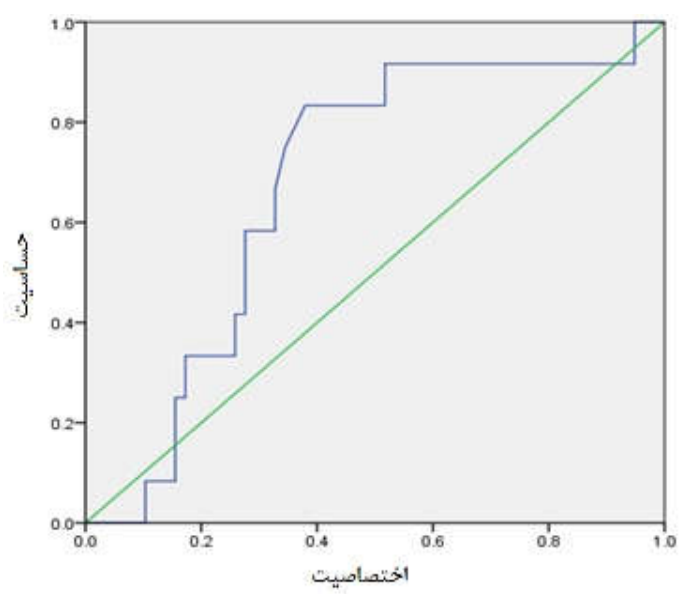

نمودار ا. منحنى راكى مربوط به سونوكرافى ورودى كانال كاريال

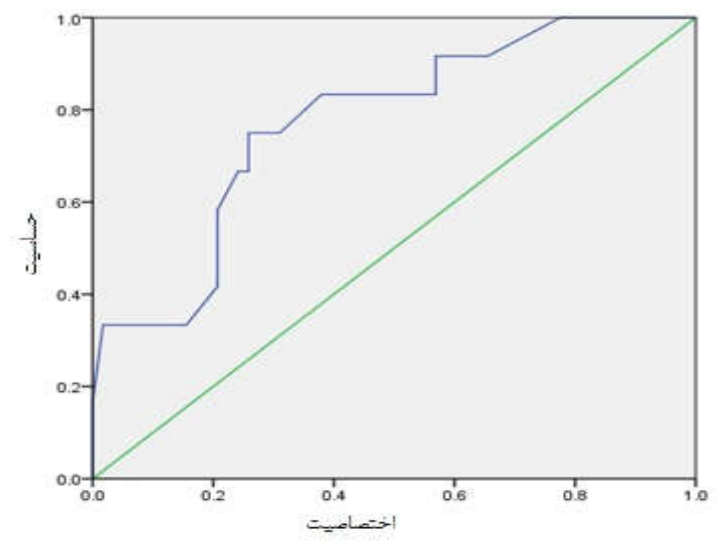

نمودار ז. منحنى راكى مربوط به سونوكرافى خروجى كانال كاريال 


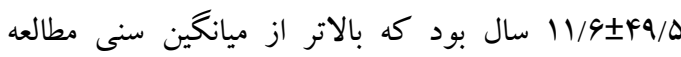

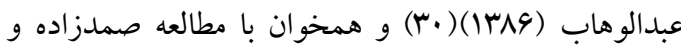

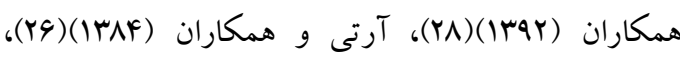
Rayegani

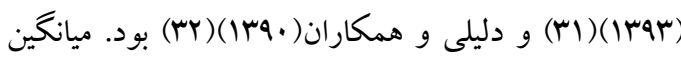

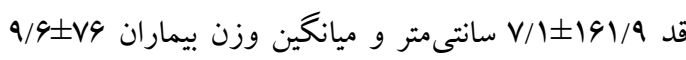

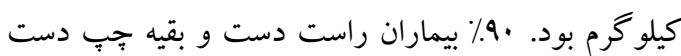

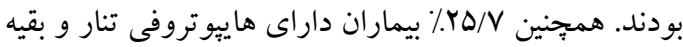
فاقد اين حالت بودند. در ميان بيمارانى كه سابقه بيمارى

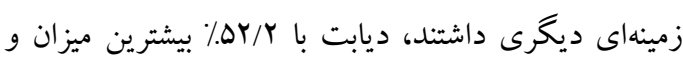

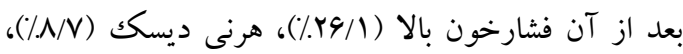

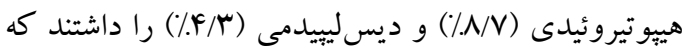
با يافتهاى مطالعه كريمى و همكاران (IraV)(IV)(

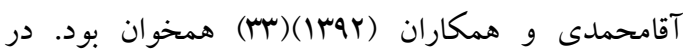

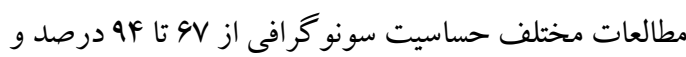

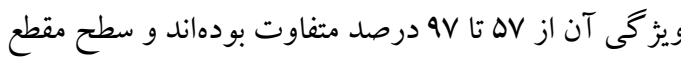
تشخيصى عصب مديان نيز از N/ه تا ها ميلىمترمربع

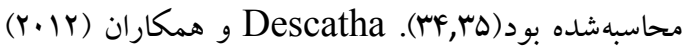

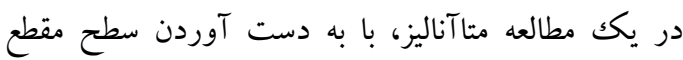

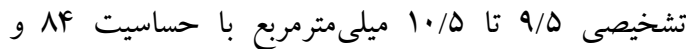
ويزكى VA درصد، نشان دادند در تشخيص CTS

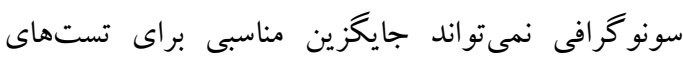

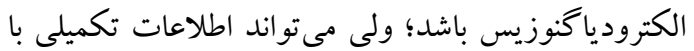
ارزشى در اختيار محققان قرار دهد(YY). در مطالعه

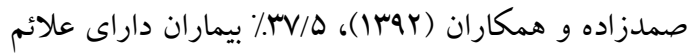
بالينى منطبق با سندرم تونل كاريال داراى نتيجه NCV

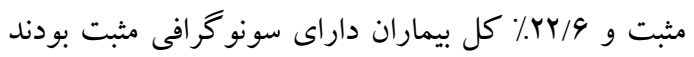

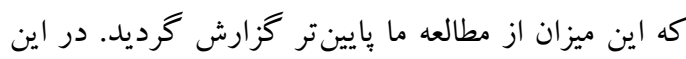

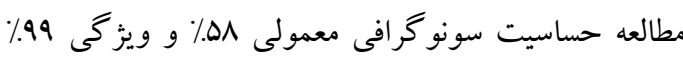

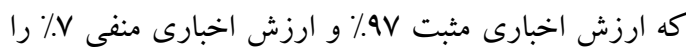

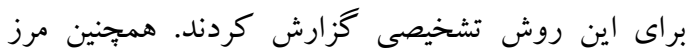
تشخيصى عصب مديان برابر 11/10 ميلىمترمربع محاسبه

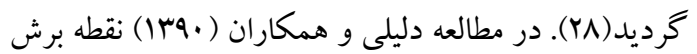
9/\% ميلىمتر در سطح مقطع نزديك، بالاترين ميزان
بحث

از ميان · لبيمار داراى علائم منطبق با سندرم تونل كاريال،

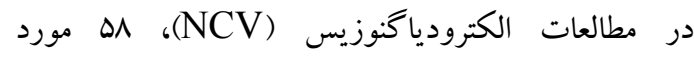

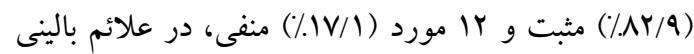

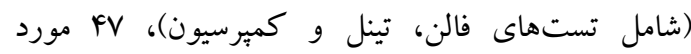
مثبت و س مورد (\%V/I/ )

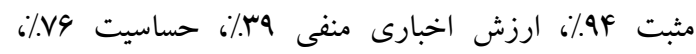

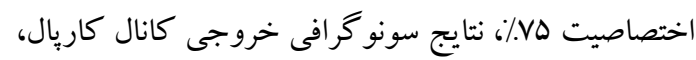

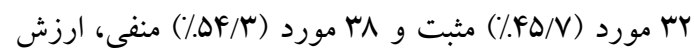

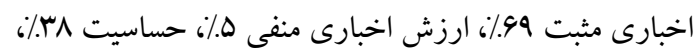
اختصاصيت IV/، نتايج سونو گرافى ورودى كانال كاريال،

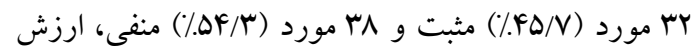
اخبارى مثبت 99/، ارزش اخبارى منفى 11/؛ حساسيت r/rV

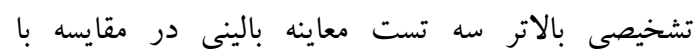
سونو گرافى داشت. البته نتايج تستهاى بالينى هر كدام

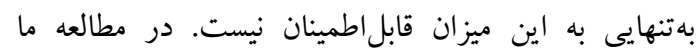

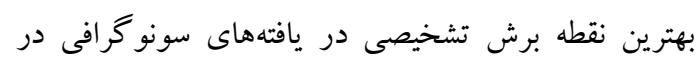

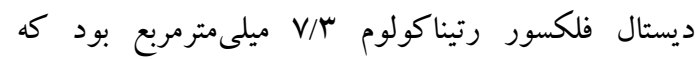

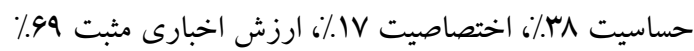
و ارزش اخبارى منفى هـ داشت. همجنين در برو گزيمال

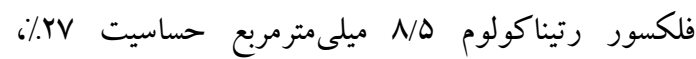

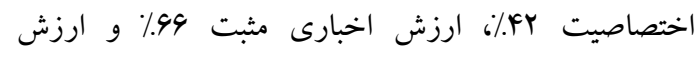
اخبارى منفى 11٪ داشت. بر اساس يافتهاى اين تحقيق،

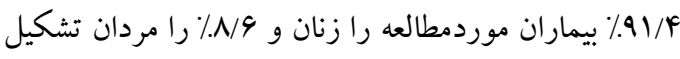

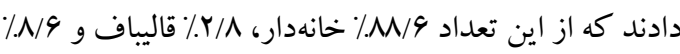

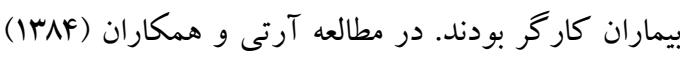

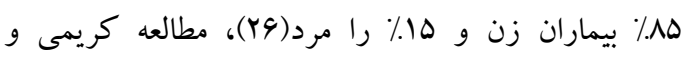

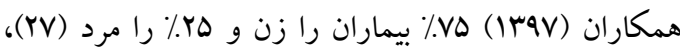

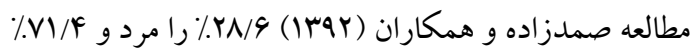

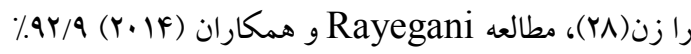

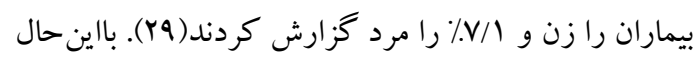

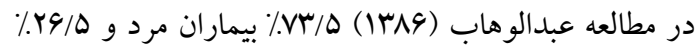

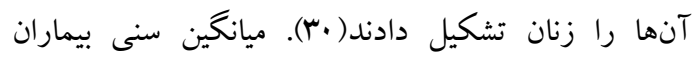


الكترودياكنوزيس عصب مديان در ناحيه مج دست است. از

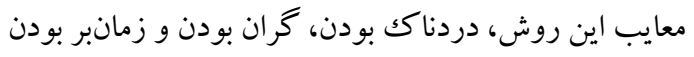

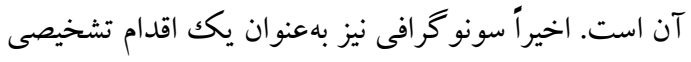

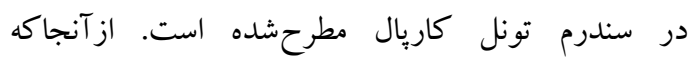
سونو گرافى بدون درد بوده و هزينه كمى دارد، بيماران

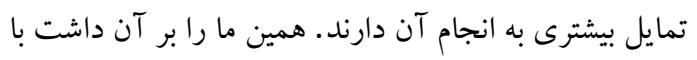

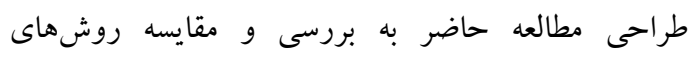
تشخيصى سندرم تونل كاريال بيردازيم. بر اساس نتايج

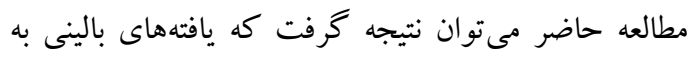
ميزان زيادى در تشخيص سندرم تونل كاريال مى تواند كمكك كننده باشد. همين امر دقت بيشتر در انجام معاينات دئن

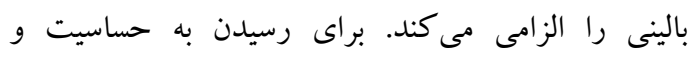

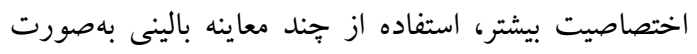

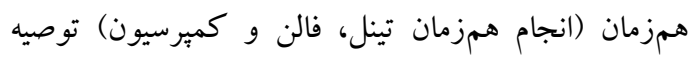

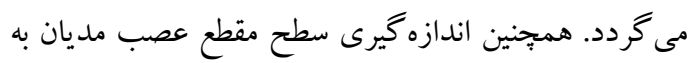

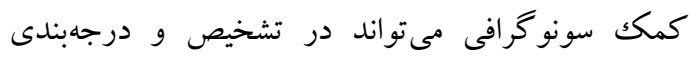
شدت سندرم تونل كاريال مفيد باشد. با استفاده از

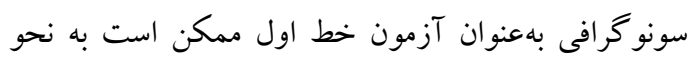
مؤثرى ميز ان مطالعات هدايت عصبى كاهش يابد. با اين حال

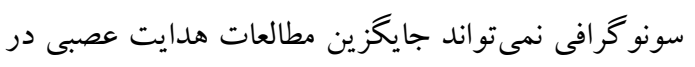
تشخيص سندرم تونل كارب كردد.

\section{تشكر و قدردانى}

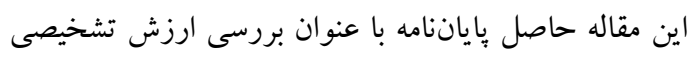

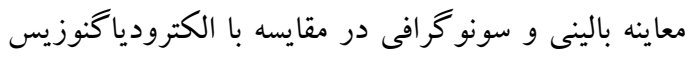
در تشخيص سندرم تونل كاريال در بيماران مراجعه كننده به دونه

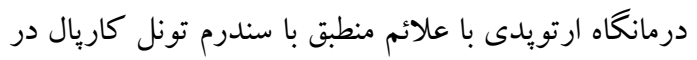

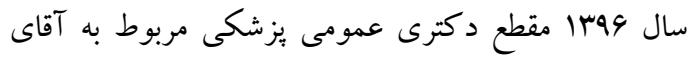

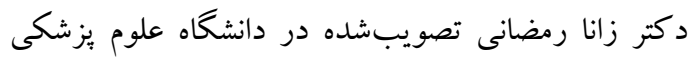
كردستان با كد طرح:

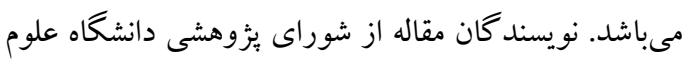

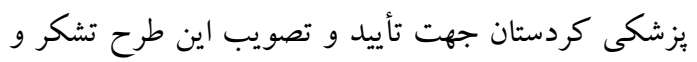

$$
\text { قدردانى مىنمايند. }
$$

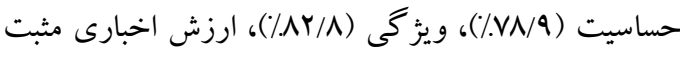

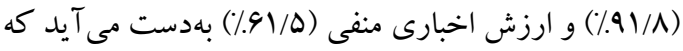

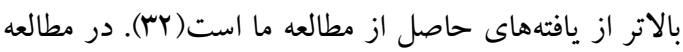
ملكى و همكاران (سابץ ا) بالاترين دقت تشخيصى در نقطه برش ه/ \$ ميلىمترمربع در قسمت ورودى تونل كاريال بال

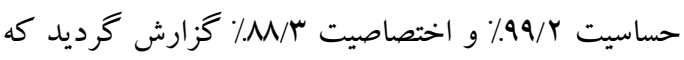

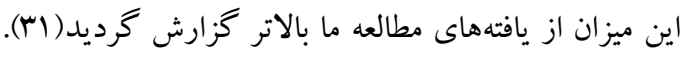

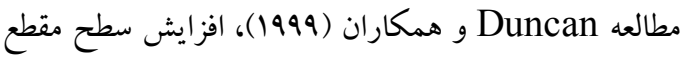
عصب مدين برو ززيمال به محل ورود به تونل كاريال، در

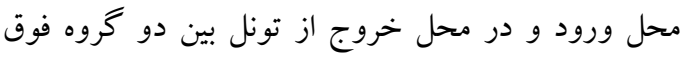

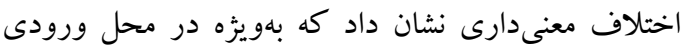

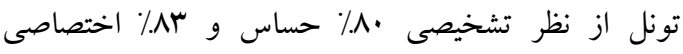

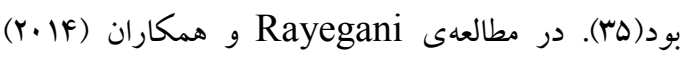

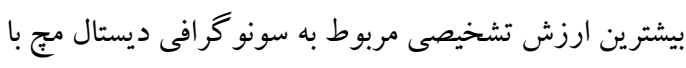

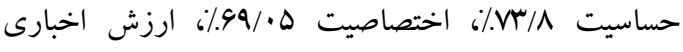

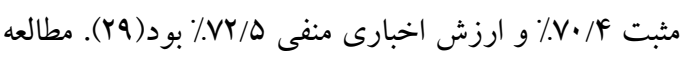
Klauser سطح مقطع عصب مدين برابر ال 11 ميلىمترمربع مىتواند

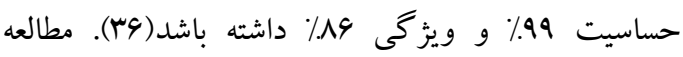

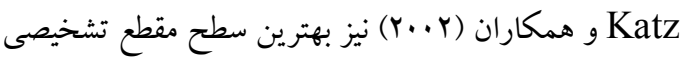

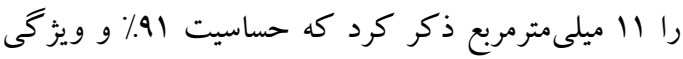
FV

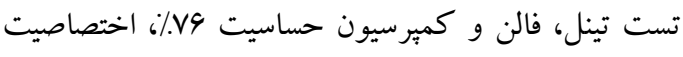

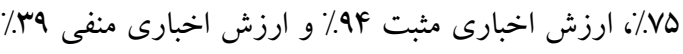

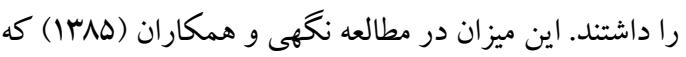
به بررسى ارزش تشخيصى تست فالن برداختند، تست فالن

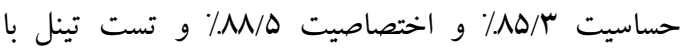

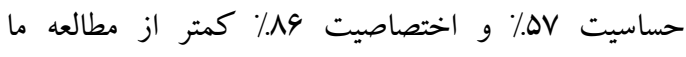

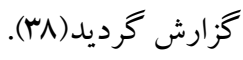

\section{نتيجه كيرى}

سندرم تونل كاريال، شايعترين مونونوروياتى كانونى فشارنده است كه در تجربه بالينى ديده مى شودد. در حال حاضر تنها روش تشخيصى قابلاعتماد اين سندرم، مطالعه 
1.Chammas M. Carpal tunnel syndrome. Chir Main. 2014; 33(2): 75-94.

منابع

2.Jenkins DB. Flexor forearm in the upper limb. In: Hollinsheads Functional anatomy of the limbs and back. 8th ed. Philadelphia: W.B. Saunders; 2002. 153-60.

3.Shapiro BE, Preston DC. Entrapment and compressive neuropathies. Med Clin North Am. 2009; 93 (2): 285-315.

4.Blumental S, Herskoritz S, Verghese J.Carpal tunnel syndrome in older adults. Muscle Nerve. 2006; 34 (1): 78-83.

5.Aroori S, Spence RA. Carpal tunnel syndrome. Ulster Med J. 2008; 77(1):6-17.

6.Bradly WG, et al. Neurology in Clinical Practice. Butter Worth: Heinemann; 2004.

7.Lewis PR, Merritt S. neurology. Philadelphia: Lippincott Williams \& Wilkins; 2000.

8.Tindall SC. Chronic injures of peripheral nerves by entrapment. In: Youmans JR. Neurological Surgery. W.B Saunders. 1996; 2:182-2209.

9.Phillips E. Carpal tunnel and ulnar tunnel syndrome and stenosing tenosynovitis. In: S. Terry Canale,Campbells operative orthopaedics. New York: mosby; 1998:3685-94.

10.Koyuncuoglu HR, Kutluhan S, Yesildag A, Oyar O, Guler K, Ozden A. The value of ultrasonographic measurement in carpal tunnel syndrome in patients with negative electrodiagnostic tests. Eur J Radiol. 2005; 56: 365-69.

11.Mallohi A, Pulzl P, Trieb T, Piza H, Bodner G. Predictor of carpal tunnel syndrome: Accuracy of gray scale and color doppler sonography. AJR. 2006; 186(5):1240-5.

12.Buchberger W, Judmaier W, Birbamer G, Lener M, Schmidauer C. Carpal tunnel syndrome. AJR. 1992; 59: (4)793-8.

13.Beckman R, Visser LH. Sonography in the diagnosis of carpal tunnel syndrome: A critical review of the literature. Muscle Nerve. 2003; 27(1):26-33.

14.Sarria 1, Cabada T, Cozcolluela R, Martinez-Berganza T, Garcia S. Carpal tunnel syndrome: Usefulness of sonography. EurRadiol. 2000; 10(12):1920-5.

15.GassnerEm, Schocke M, Peer S, Schwabegger A, Jaschke W, Bodner G. Persistent median artery in the carpal tunnel: Color Doppler ultrasonographic finding. J Ultrasound Med. 2002; 21(4):455-61.

16.Mondelli M, Filippou G, Gallo A, Ferdiani B. Diagnostic utility of ultrasonography versus nerve conduction studies in mild carpal tunnel syndrome. Arthritis Rheum. 2008; 59(3):35766.

17.El Miedany YM, Aty SA, Ashour S. Ultrasonography versus nerve conduction study in patients with carpaltunnel syndrome: Substantive or complementary tests? Rheumatology. 2004; 43:887-95.

18.Atroshi I, Gummesson CH, Johnson R, Ournstein E. Diagnostic properties of nerve conduction tests in population based carpal tunnel syndrome. BMC Musculoskelet Disord. 2003; 4:34-8.

19.Redmond D, Rivner M. False positive electro diagnostic tests in carpal tunnel syndrome. Muscle Nerve. 1988; 11: 511-8.

20.Cevik MU, Altun Y, Uzar E, Acar A, Yucel Y, Arikanoglu A, et al. Diagnostic value of Fwave inversion in patients with early carpal tunnel syndrome. NeurosciLett. 2012; 508: 11013.

هجلم علمى دانشَّاه علوه بِرشكى كردستان / دوره بيست و پِنج / بهدن و اسفند 9هسا 


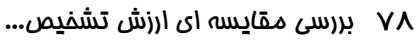

21.Roll SC, Case-Smith J, Evans KD. Diagnostic accuracy of ultrasonography VS electromyography in carpal tunnel syndrome: A systematic review of literature. Ultrasound in Med. \& Biol. 2011; 37(10):1539-53.

22.Descatha A, Huard L, Aubert F, Barbato B, Gorand O, Chastang JF. Meta-analysis on the performance of sonography for the diagnosis of carpal tunnel syndrome. Semin Arthritis Rheum. 2012; 41:914-22.

23.Bilkis S, Loreman DM, Eldridge JA, et al. Modified Phalen's test as an aid in diagnosing carpal tunnel syndrome. Arthritis Care Res (Hoboken). 2012; 64 (2): 287-9.

24. Ma H, Kim L. The diagnostic assessment of hand elevation test in carpal tunnel syndrome. J Korean NearosurgSoc. 2012; 52 (5): 472-5

25.Dumitru D. Electrodiagnostic medicine. 2nd edition. Hanley \&Belfus. 2001; 1058-62.

26.arti H, abrishamkar S, dahghan M. Comparison of treatment results of carpal tunnel syndrome by open surgical technique and arthroscopic release. J Shahrekord Univ Med Sci.2005;7(1):30-38.

27.KarimiN, TabriziN, MoosaviM, YadanicharattiJ. Prevalence of Carpal Tunnel Syndrome and Associated Risk Factors. J MazandaranUniv Med Sci. 2017; 26(146): 179-84.

28.Samadzadeh S, Motameni M, Rezaei M, Rezaei C, Faroukhi J. The comparison between ultrasonography and electrodiagnosis value in diagnosing carpal tunnel syndrome, J Kermanshah Univ Med Sci. 2013; 17(4):e77101.

29.Rayegani S.M, Kargozar E, Eliaspour D, Raeissadat S.A, Sanati E, Bayat M. Diagnostic Value of Ultrasound Compared to Electro Diagnosis in Carpal Tunnel Syndrome. Patient SafQualImprov. 2014; 2(4):142-47.

30.Abdolvahab M. A study of the ergonomics carpal tunnel syndrome (C.T.S). mrj. 2007; 1 (1):11-15.

31.Maleki N, Azami A, Anari H, Iranparvar Alamdari M, Tavosi Z, Hajaty S. Value of ultrasonography in the diagnosis of carpal tunnel syndrome confirmed by nerve conduction study. SJKU. 2014; 19 (4):58-66.

32.Dalili A, Mardani--kivi M, Alizadeh A, Hatamian H, Hoseininejad M, Peyrazm H, et al. Comparison between Sonography and Electrodiagnostic Testing in the Diagnosis of Carpal Tunnel Syndrome. JAP. 2011; 2 (5):43-51

33.Aghamohammadi-Kalkhoran, M., Rostamnejad, M., AfzaliFard, H. Risk factors for carpal tunnel syndrome: A case-control study. Journal of Paramedical Sciences \& Rehabilitation. 2013; 2(1): 49-54.

34.Buchberger W, Judmaier W, Birbamer G, Lener M, Schmidauer C. Carpal tunnel syndrome. AJR. 1992; 59(4):793-8.

35.Duncan I, Sullivan P, Lomas F. Sonography in the diagnosis of carpal tunnel syndrome. AJR.1999; 173(3):681-4.

36.Klauser AS, Halpern EJ, De Zordo T, Feuchtner GM, Arora R, Gruber J, et al. Carpal tunnel syndrome assessment with US: Value of additional cross-sectional area measurements of the median nerve in patients versus healthy volunteers. Radiology. 2009; 250(1):171-7.

37.Katz JN, Simmons BP. Clinical practice: Carpal tunnel syndrome. N Engl J Med. 2002; 346(23):1807-12.

38.Negahi A, Rahimi A. Diagnostic value of phalen's test and nerve conduction velocity in carpal tunnel syndrome. Hormozgan Medical Journal. 2007, 11(2); 103-7. 